\title{
An Experimental Study of Fire Suppression Physics for Sprinkler Protection
}

\author{
JAAP DE VRIES, YIBING XIN, and KARL MEREDITH \\ FM Global \\ 1151 Boston-Providence Turnpike \\ Norwood, MA 02062 USA
}

\begin{abstract}
An experimental study was conducted to investigate the key physics of sprinkler-based fire suppression and associated water-film transport. The objective was to evaluate experimental methods for their appropriateness in studying the fundamental physics, and provide validation data for numerical modeling. The numerical model is currently under development to simulate sprinkler-based suppression of largescale, rack-storage fires. Individual experimental techniques were explored to study water absorption, surface flow, evaporation, and suppression on vertically arranged, corrugated cardboard surfaces. In addition, water transport was investigated in full-scale rack storage configurations. The experimental results show that the tested experimental techniques are appropriate to study the key phenomena related to sprinkler-based fire suppression.
\end{abstract}

KEYWORDS: suppression, sprinklers, water transport, ignition, heat release rate.

\section{INTRODUCTION}

Water-based automatic sprinklers are widely used in industrial facilities and buildings to reduce fire losses and for fire safety purposes. Water is an ideal suppression agent due to its thermal properties, accessibility, and high expansion ratio during vaporization [1]. Much progress on water-based fire suppression has been made in the past concerning water mist applications [2-4] and sprinkler/plume interaction [5,6]. However, fundamental studies on the physics of water-based sprinkler suppression are scarce, and prediction of the effectiveness of sprinkler protection, given a particular fire scenario, remains a major challenge for the fire community [7].

Current methods of evaluating sprinkler performance rely solely on full-scale tests. Typically, full-scale tests simulate a fire protection scenario from which several global quantities are assessed, such as number of sprinklers activated, ceiling temperatures, extent of fire spread and post-test assessment of damage in the main and target fuel arrays. Since the cost of each full-scale test is very high, parametric analysis of each individual variable, such as ceiling/storage height, flue space, commodity type, sprinkler characteristics, water pressure, and ignition location becomes prohibitively expensive. To guide the understanding of the effects of these parameters, FM Global initiated a fire modeling and sprinkler technology program in 2008 with the ultimate goal of developing a numerical model to predict sprinkler-based suppression of largescale, rack-storage fires. The intent of this model is to include adequate physical phenomena to allow for parametric studies and trend analysis.

In the current model, the gas-phase chemistry and flow are simulated using FireFOAM - an OpenFOAMbased CFD solver [8]. The flame heat transfer is calculated using a smoke-point-based soot-radiation model [9], coupled with a pyrolysis model in the solid phase based on flammability measurements using the fire propagation apparatus [10]. The transport of sprinkler spray is simulated using a Lagrangian particle transport scheme with initial spray conditions determined from shadow imaging experiments [11]. This FireFOAM model will integrate with a new water-transport model for sprinkler suppression currently under development [12]. The development of this later model, however, requires in-depth knowledge of fire suppression physics including sprinkler sprays, water absorption, surface flows, and surface suppression. Ideally, individual phenomena need to be studied to guide model development and provide validation data.

The objective of the present work is to test a variety of experimental techniques and evaluate their appropriateness in assessing the key physics included in this water-transport model. The entire suppression problem was broken up into several smaller studies focusing on water-film transport and interactions with solid fuel surfaces. 
In the next section, the governing equations of the water-transport model are presented, followed by a description of the experimental apparatus used in this study including the calibration of several of its components. Finally, experimental results are reported and discussed including water absorption, water flow patterns and rivulet formation, water movement on rack storage arrangements, and single/parallel panel evaporation and suppression. The results presented herein are primarily intended to examine the importance of selected physical effects for fire suppression and to guide future studies.

\section{SUPPRESSION MODELING FRAMEWORK}

The focus of the current suppression model is to simulate water transport on solid fuel surfaces and to simulate interactions of water flows with the gas and solid phase. Shown in Fig. 1 is a two by four by three array of Class II commodity underneath the water application apparatus (WAA) located at FM Global's Research Campus. Described in Fig. 1 are several of the phenomena involved during fire suppression, such as partial wetting, rivulet flow, vaporization, absorption, corner flow, and water/fire interaction. All these phenomena are included in the suppression model as described in detail by Meredith et al. [12]. Some experiments concerning corner flow and flows on vertical surfaces are described in more detail elsewhere [13].

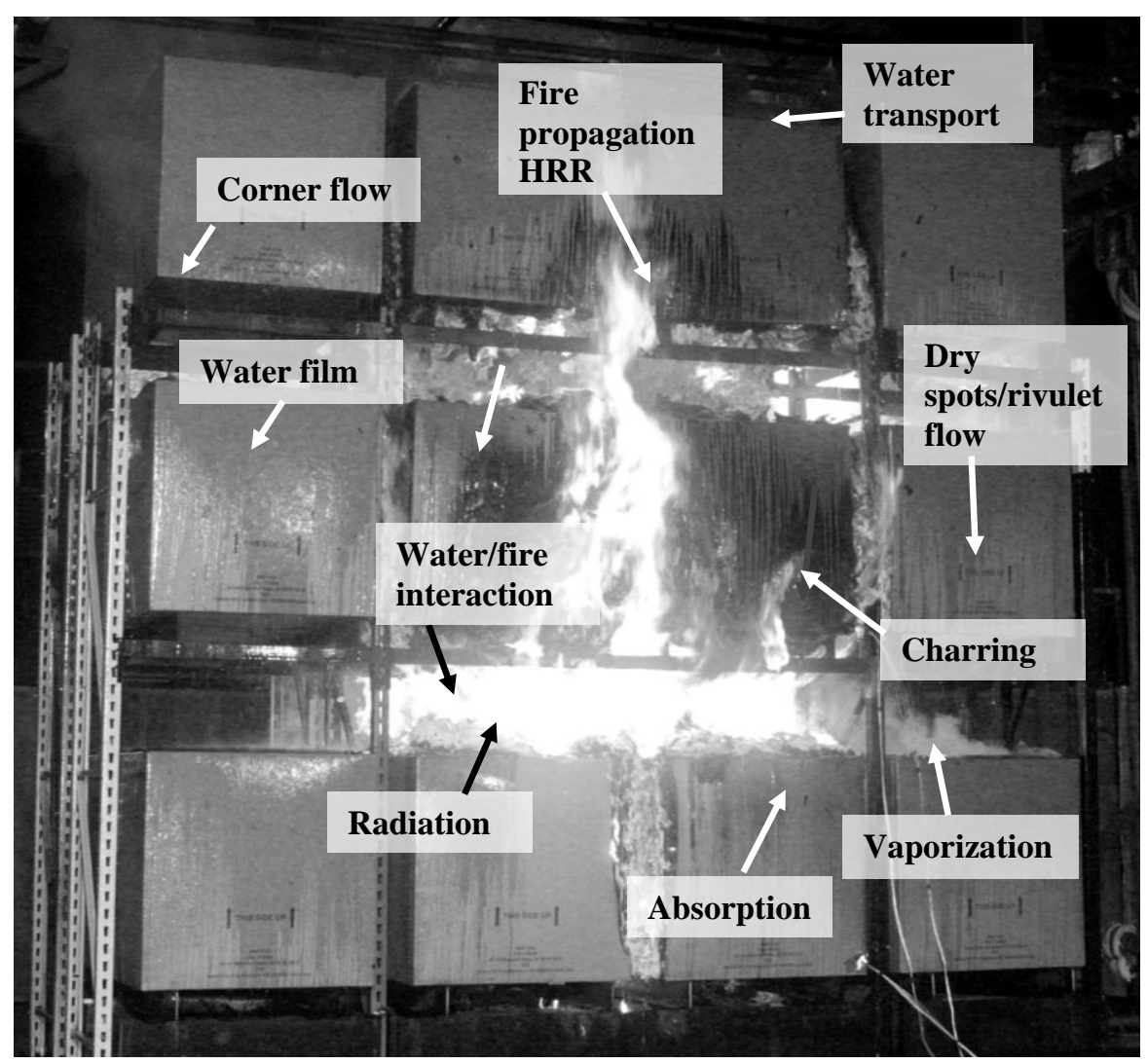

Fig. 1. Overview of individual phenomena involved in fire suppression.

In case of film flow, physical processes occur both in the surface normal and tangential direction. Due to the thin nature of the film $(<1 \mathrm{~mm})$, flow in the normal direction can be assumed negligible. In addition, the diffusive transport of mass/momentum/energy in the surface-normal direction will dominate, while the tangential diffusion will be negligible in comparison. This assumption is aplicable for both continuous films as well as discontinous rivulets, with correction terms added to account for tangential effects along rivulet contact lines [12]. 


\section{Governing Equations}

The basic equations used in the suppression model consist of the mass continuity, momentum transport and energy transport equation and are given here. Only a short summary of the equations are given here. A more detailed description including a nomenclature section detailing each source term is presented by Meredith et al. [12].

\section{Mass Continuity}

The mass continuity, integrated over the film thickness, is given by

$$
\frac{\partial \rho \delta}{\partial t}+\nabla_{s} \cdot[\rho \delta \mathbf{U}]=S_{\rho \delta, i m p}+S_{\rho \delta, s p l a s h}+S_{\rho \delta, v a p}+S_{\rho \delta, a b s}+S_{\rho \delta, s e p}
$$

In Eq. $1, \rho_{l}$ is the liquid density, $\delta$ is the film thickness, $t$ is time, and $\mathbf{U}$ is the two-dimensional tangential velocity field. The quanities on the right-hand side represent the mass flow rate per unit wall area due to impingement, splashing, evaporation, absorption into the solid, and film separation when the water leaves the solid fuel surface.

\section{Momentum Transport}

The momentum equation, integrated over film thickness, is given by

$$
\begin{aligned}
& \frac{\partial \rho \delta \mathbf{U}}{\partial t}+\nabla_{s} \cdot[\rho \delta \mathbf{U U}]=-\delta \nabla_{\mathbf{s}}\left(p_{i m p}+p_{s p l a s h}+p_{v a p}+p_{\sigma}+p_{\delta}+p_{g}\right)+ \\
& \boldsymbol{\tau}_{g}-\boldsymbol{\tau}_{w}+\boldsymbol{\tau}_{m a r}+\rho \mathbf{g}_{t} \delta+\mathbf{F}_{\theta}+\mathbf{S}_{\rho \delta \mathrm{U}, \text { imp }}+\mathbf{S}_{\rho \delta \mathrm{U}, \text { splash }}+\mathbf{S}_{\rho \delta \mathrm{U}, \text { sep }}
\end{aligned}
$$

In Eq. 2, $p$ is comprised of forces in the wall-normal direction representing spray impingement, splashing, vaporization (also known as the vapor recoil effect), surface tension, hydrostatic pressure, and local gasphase pressure. $\tau_{g}$ and $\tau_{w}$ represent the shear stress (tangential to the wall) with respect to the water film-gas interface and the water film-solid wall interface, respectively. In most cases $\tau_{g}<<\tau_{w}$. $\tau_{\text {mar }}$ represents the shear stress due to temperature dependant surface tension gradients. The shear stress term $S_{\rho \delta U}$ is the momentum source per unit wall. Stresses included in this model are due to impingement, splashing, vaporization, and film separation into the gas phase. In addition, the viscous shear stress (at the gas/liquid and wall/liquid interfaces), thermocapillary stress, gravity body force, and contact-angle force are also included.

\section{Energy Transport}

The enthalpy form of the film energy transport equation is represented by

$$
\frac{\partial \rho \delta h}{\partial t}+\nabla_{s} \cdot[\rho \delta \mathbf{U} h]=\dot{q}_{g}^{\prime \prime}+\dot{q}_{w}^{\prime \prime}+S_{\rho \delta h, v a p}+S_{\rho \delta h, r a d}+S_{\rho \delta h, i m p}+S_{\rho \delta h, s p l a s h}+S_{\rho \delta h, s e p}+S_{\rho \delta h, a b s} .
$$

In Eq. 3, the mean enthalpy $h$ is evaluated at the mean film temperature $T_{f}$. The energy source terms on the right-hand side represent the heat fluxes from the gas phase and the solid wall, and other source terms due to water evaporation, incident radiation, droplet impingement, splashing, water flow separation, and absorption by the solid fuel.

Sub-models are required for the source terms shown in Eqs. 1, 2, and 3. More details concerning the submodels are discussed by Meredith et al. [12]. Since only limited knowledge exists for most of these submodels, experimental studies are needed, especially for the key phenomena such as water absorption, splashing, rivulets, corner flows, water-transport in rack storage, evaporation, and suppression. The experimental set-up used to study some of these phenomena will be discussed next. 


\section{EXPERIMENTAL METHODS}

Four major experimental set-ups were used in the present work. First, water absorption by corrugated cardboard was measured both on a static horizontal sample and on a vertical wall exposed to a free-falling film. Second, water evaporation, formation of dry spots, and piloted ignition times (corrugated only) were measured on vertical walls using both inert materials and corrugated cardboard. Third, the transport of water in a rack storage configuration was studied. Finally, suppression, using water flows, of parallel panels was investigated.

\section{Water Absorption}

Water absorption, (term $S_{\rho \delta, a b s}$ and $S_{\rho \delta h, a b s}$ in Eqs. 1 and 3), was measured both using a Cobb test (ISO 535, ASTM 3285, TAPPI 441 [14]) and on vertical walls exposed to water films. For the Cobb test, a cardboard sample was weighed before being placed on the mat and sealed with the gasket by tightening the clamps against a metal ring. The metal ring has an inner diameter of $11.3 \mathrm{~cm}$ and vertical height of $2.5 \mathrm{~cm}$. A total of $100 \mathrm{~mL}$ water was then poured into the ring, creating a $1 \mathrm{~cm}$ water layer on top of the corrugated cardboard sample. After a predetermined exposure time, the sample was taken out of the Cobb apparatus, with excess surface water removed, and then weighed again on a digital scale. All corrugated samples used for the Cobb tests were pre-conditioned in a climate chamber $\left(T=23.0 \pm 1.0{ }^{\circ} \mathrm{C}, R H=50.0 \pm 2.0 \%\right)$ according to ASTM D 685-93.

For the vertical wall absorption test, a sample of tri-wall corrugated cardboard was sealed on the back surface and around the edges using clear packing tape (HD Clear, $7.6 \mathrm{~cm}$ wide) leaving an exposed surface of $19.5 \mathrm{~cm}$ wide and $45.5 \mathrm{~cm}$ long. A water film was allowed to flow over the vertical sample surface for a predetermined amount of time. The sample was weighted before and after each test to determine total absorption. Flow rates per unit width $(\Gamma)$ between 0.16 and $0.30 \mathrm{~kg} / \mathrm{s} \cdot \mathrm{m}$ were used in the tests.

\section{Single Wall Evaporation and Ignition Tests}

All wall evaporation and ignition experiments (terms $S_{\rho \delta \text {,vap }}, P_{v a p}$ and $S_{\rho \delta h, v a p}$ in Eqs. 1 to 3), with external heating were performed underneath a $1 \mathrm{MW}$ fire products collector (FPC). The external heat flux was provided by a propane-fed radiant heater. The evaporation rates were measured both using a collection bin on a load cell and by humidity probes installed inside the exhaust duct of the 1 MW FPC. Ignition times were measured on corrugated cardboard through visual observation of first occurrence of flames.

\section{Fire Product Collector (FPC)}

The $1 \mathrm{MW}$ FPC consists of a $3.2 \mathrm{~m}$ diameter cone collector placed $3.4 \mathrm{~m}$ above floor level. The coneshaped collector reduces to a $66 \mathrm{~cm}$ diameter duct. A $39 \mathrm{~cm}$ diameter orifice plate is placed at the entrance of the duct to allow for uniform mixing at the measurement station. Four pitot probes, a static probe, and a gas sampling probe were placed 6.2 diameters downstream of the orifice plate. Total hydrocarbon content of the exhaust gas was measured via a flame ionization detector (Rosemount Analyzer Inc. 195003). Carbon dioxide, carbon monoxide, and oxygen were measured using a gas analyzer (Rosemount NGA 2000). All gas measurements were synchronized with measurements made on the floor level and sent to a data acquisition system (16 bit, $10 \mathrm{~Hz})$ via fiber-optic cables. Previous calibration has shown that the FPC can measure heat release rates, flow rates, and unburned hydrocarbon levels to within $6.6 \%(95 \%$ confidence). The flow rate through the $1 \mathrm{MW}$ FPC can be adjusted up to $5.66 \mathrm{~m}^{3} / \mathrm{s}$ at room temperature.

\section{Radiant Panel}

An industrial heating panel (Detroit Radiant, Model DR-160, $46.9 \mathrm{~kW}$ ) was used in this study to simulate flame radiation (term $S_{\rho \delta h, r a d}$ in Eq. 3). Industrial-grade (97\% purity) propane was sent through a gas filter to remove dirt, water, and oil particles and droplets down to $0.01 \mu \mathrm{m}$. Gas flow rates were monitored using a gas flow meter (Teledyne Hastings HFM301, 0-600 standard L/min). The radiant panel consumed $25.9 \pm 0.2 \mathrm{~L} / \mathrm{min}$ of propane and was calibrated using three Schmidt-Boelter type heat flux gauges (0$200 \mathrm{~kW} / \mathrm{m}^{2}$, MedTherm \#64-20SB-72-20KS). The surface temperature of the panel was determined by fitting a Planck function through a spectral distribution obtained using a mid-infrared spectrometer (Spectraline Inc. Model ES-200, 1-5 $\mu \mathrm{m}$ ). The surface temperature was found to be $1225 \mathrm{~K}$ with an 
effective emissivity of 0.493 . Therefore, the total hemispherical emissive power at the panel surface was $63 \mathrm{~kW} / \mathrm{m}^{2}$. Before each test, the panel was operated for ten minutes to reach steady state.
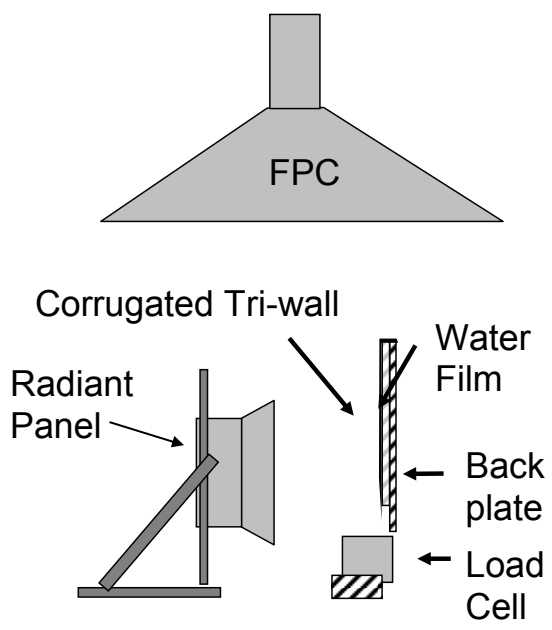

Fig. 2. Schematic of experimental set-up used for vertical panel experiments.

\section{Single-Wall Set-Up}

Figure 2 shows the experimental set-up used for the single wall tests in which two different materials were used. First, corrugated tri-wall cardboard (AAA flutes, $1.9 \mathrm{~kg} / \mathrm{m}^{2}$ ) was exposed to radiant heat flux to measure evaporation rate and piloted ignition time. Second, a $0.16 \mathrm{~cm}$ aluminum plate was insulated on the back side $(5.1 \mathrm{~cm}$ Koawool) and painted on the front with carbon black (MedTherm, $\alpha=0.96)$. For the aluminum plate experiments, a $46 \mathrm{~cm}$ wide, and $41-\mathrm{cm}$ high, window cut out of a polished-aluminum sheet was placed between the radiant panel and the target surface. Water flow into the system was measured via a turbine flow meter (0-44 g/s, Signet 6F 3-2000-11). Run-off water from the vertical surface was collected inside a stainless steel collection bin placed on a load cell (0-181 kg, GSE Series 4440). The load cell was calibrated using several precision masses and found to be accurate within $\pm 10 \mathrm{~g}$. The flow meter was then calibrated using the load cell. Uncertainties for the flow meter were found to be less than $1 \%$ of the measured value. Since the evaporation rates were determined as the difference between the inflow and outflow, lower evaporation rates led to higher uncertainties.

Piloted ignition times of vertical, tri-wall corrugated cardboard panels were measured below the $1 \mathrm{MW}$ FPC for radiant heat fluxes ranging from 15 to $35 \mathrm{~kW} / \mathrm{m}^{2}$. The ignition time was defined as the duration between the time of exposure to radiation and the appearance of visible flames on the surface. A polished aluminum shield was placed between the radiant panel and the corrugated cardboard and removed rapidly to create a well-defined time zero. A line igniter was used as an ignition source. The line igniter was made of a $1.3 \mathrm{~cm}$ stainless-steel tube perforated with sixty, $1 \mathrm{~mm}$ diameter holes. Flames from the line igniter were placed $\pm 2.5 \mathrm{~cm}$ normal to the corrugated paperboard surface. Gas flow (propane) through the igniter was measured using a mass flow meter (HFM-301 Teledyne Hastings, $0-600 \mathrm{~L} / \mathrm{min}$ ), and set to $0.5 \mathrm{~L} / \mathrm{min}$.

\section{Humidity Probe Measurements}

An alternative method for measuring evaporation rates (terms $S_{\rho \delta, v a p}, P_{v a p}$ and $S_{\rho \delta h, v a p}$ in Eqs. 1 and 3), was examined using two separate humidity probes, one on the lab floor and the other one inside the exhaust duct of the 1 MW FPC. Water concentration was determined from the relative humidity and temperature as

$C_{H 2 O}=(R H / 100)\left(P_{v a p}(T) / R_{u} T\right) M_{H 2 O}$.

In Eq. $4, C_{H 2 O}$ is the water mass concentration $\left(\mathrm{g} / \mathrm{m}^{3}\right), R H$ is the relative humidity $(\%), R_{u}$ is the universal gas constant $(8.314 \mathrm{~J} / \mathrm{mol} \cdot \mathrm{K}), T$ is the temperature $(\mathrm{K}), M_{H 2 O}$ is the molecular weight of water $(\mathrm{g} / \mathrm{mol})$, and 
$P_{\text {vap }}(T)$ is the saturated vapor pressure of water. The empirical correlation from Lowe and Ficke [15] was used to calculate $P_{v a p}(T)$. The mass flow of vaporized water then can be calculated by

$$
\dot{m}_{H 2 O}=\dot{V}_{\text {Duct }}\left(C_{H 2 O, D u c t}-C_{H 2 O, L a b}\right) .
$$

In Eq. $5, \dot{m}_{H 2 O}$ is the mass flow of evaporated water $(\mathrm{g} / \mathrm{s}), \dot{V}_{D u c t}$ is the volumetric flow rate through the duct $\left(\mathrm{m}^{3} / \mathrm{s}\right), C_{H 2 O, \text { Duct }}$ is the water concentration in the FPC's duct $\left(\mathrm{g} / \mathrm{m}^{3}\right)$, and $C_{H 2 O, L a b}$ is the water concentration on the lab floor $\left(\mathrm{g} / \mathrm{m}^{3}\right)$. In this study, Eqs. 4 and 5 and the Kline-McClintock method [16] were used to determine the uncertainty. Figure 3 shows the measured water vapor flow through the $1 \mathrm{MW}$ FPC compared to the estimated water production from the $40 \mathrm{~kW}$ radiant panel. The uncertainty analysis above showed significant uncertainties associated with the measured water vapor flow rate. However, good agreement is observed between the measured water vapor flow rates and the calculated values based on the fuel supply. The main source of experimental uncertainty in Eq. 4 is due to the small difference between vapor concentrations in the duct and in the lab. The results confirmed that the humidity-probe method can be successfully applied to determine evaporation rates, particularly when water collection onto a load cell is not feasible in fire suppression experiments. The uncertainty is a strong function of the duct flow rate. Therefore, using a smaller fire products collector $(0.2 \mathrm{MW})$ would reduce the uncertainty to $<15 \%$.

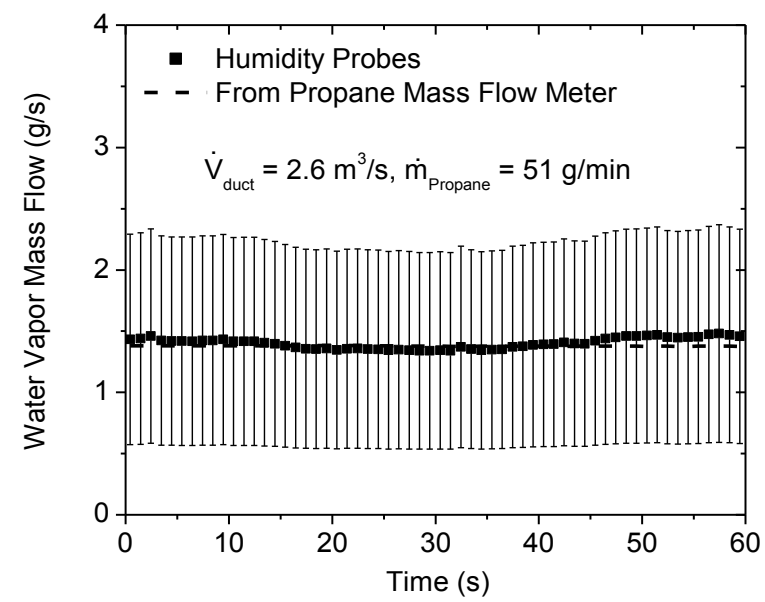

Fig. 3. Measurements of water vapor flow rate using humidity probes and the water production based on propane burning rate.

\section{Water Transport in Rack Storage}

While water absorption, evaporation, and surface flow can be measured with reasonable accuracy on vertical surfaces, the water transport on real commodities is more complex due to factors related to the fuel and the storage geometries causing flow separation and splashing (terms $S_{\rho \delta, \text { splash }}, P_{\text {splash }}, S_{\rho \delta U, \text { splash }}, S_{\rho \delta U, s e p}$ $S_{\rho \delta h, s e p}$, and $S_{\rho \delta h, s p l a s h}$ in Eqs. 1 to 3),. Examples of the complexities are packaging of the corrugated cardboard boxes (taping and folding), alignment of boxes, and spacing between boxes. For these reasons, the water transport on real, rack-storage commodities was investigated with an emphasis on tier-to-tier transport efficiency. All experiments were carried out at room temperature under no fire conditions. The experiment was set up directly under a water application apparatus (WAA). The WAA was designed to deliver a uniform water flux via 48 nozzles over a $17.84 \mathrm{~m}^{2}$ coverage area. Water fluxes of 4.1, 12.2, and $24.4 \mathrm{~L} / \mathrm{min} \cdot \mathrm{m}^{2}$ were used in this study. The fuel arrays used in the tests were two-pallet-load long, twopallet-load wide and three-tier high rack storage of Class 2 commodity excluding the wood pallets. The flue space was $0.15 \mathrm{~cm}$ in both longitudinal and transversal directions. The corrugated cardboard boxes had nominal dimensions of $1.07 \mathrm{~m} \times 1.07 \mathrm{~m} \times 1.07 \mathrm{~m}$. Twelve pans were places alongside the bottom perimeter of each box. The water collected by each pan was directed to a $20 \mathrm{~cm}$ diameter PVC tube via $1.27 \mathrm{~cm}$ diameter flexible hoses. Water levels inside the PVC tubes were measured using pressure transducers. A 
schematic of the experimental set-up is shown in Fig. 4. Water-collection tests were performed at each tier and tests were ended when one of the collection tubes had reached its full capacity of $38 \mathrm{~kg}$.

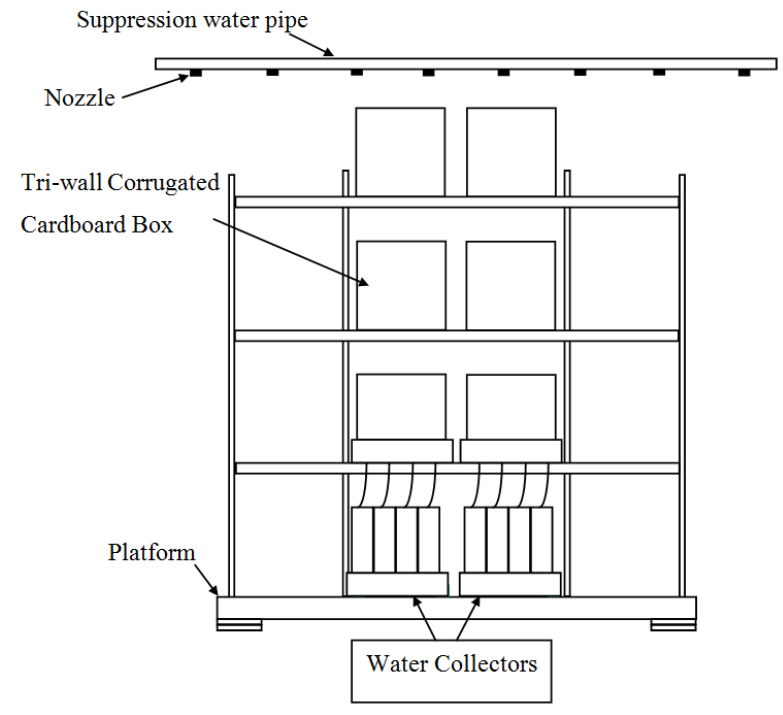

Fig. 4. Test set-up for water transport over rack-storage commodities.

\section{Parallel Panel Tests}

Eleven parallel panel tests were performed with each panel exposed to a water film. The experimental setup consisted of two $2.44 \mathrm{~m}$ high, $0.61 \mathrm{~m}$ wide tri-wall corrugated cardboard panels with a $0.31 \mathrm{~m}$ separation gap. The ignition source was a $60 \mathrm{~kW}$ sand burner placed between the bottom edges of the two panels. Water flow rates were kept constant during the tests and measured using a mass flow meter (Signet $6 \mathrm{~F}$ 3-2000-11, 0-44 g/s). Water at room temperature was applied to the panels via a perforated tube applicator located on top of each panel. Water application was started before ignition. The complete set-up was enclosed by metal screens to diffuse air draft, creating a more quiescent condition. All experiments were conducted underneath a 5 MW FPC placed $7.3 \mathrm{~m}$ above the floor. The FPC has a $6.1 \mathrm{~m}$ diameter dome converging into a $1.52 \mathrm{~m}$ diameter duct. Gas analysis was performed by the same instrumentation as described previously for the 1 MW FPC.

\section{RESULTS AND DISCUSSION}

For each of the experimental techniques described above some preliminary data was obtained. This section will present those data and discuss some of the results.

\section{Water Absorption}

Previous work by Jayaweera and Yu [17] showed that absorption into corrugated cardboard followed the Lucas-Wasburn equation [18,19]. Jayaweera and $\mathrm{Yu}$ found that the impingement force and hydrostatic force are negligible for Cobb tests [17]. Under similar assumptions for continuous falling films, the LucasWasburn equation becomes

$\frac{8 \mu_{l}}{r^{2}} z \frac{d z}{d t}=\frac{2 \sigma \cos \theta}{r}$.

In Eq. 6, $\mu_{l}$ is the liquid dynamic viscosity (Pa.s) and $z$ is the normal direction of the fuel surface $(\mathrm{m}), r$ is the average pore diameter $(\mathrm{m}), \sigma$ is the surface tension $(\mathrm{N} / \mathrm{m}), \theta$ is the contact angle between the liquid and the solid $\left({ }^{\circ}\right)$. The solution of Eq. 6 indicates that the accumulated mass scales with the square root of time 
when the hydrostatic pressure is negligible compared to the capillary effect. Figure 5 shows the absorption results for vertical panels and from Cobb tests. The accumulated absorption $\left(\mathrm{g} / \mathrm{m}^{2}\right)$ related to the source term in Eq. 1 as $\Delta m_{a b s}=\int_{0}^{L_{x}} \int_{0}^{L_{y}} \int_{0}^{t_{a b s}} S_{\rho \delta, a b s} d x d y d t$, where $L_{x}$ and $L_{y}$ are the dimension of the absorption area in the experiment and $t_{a b s}$ is the test duration. Close agreement is observed between the two different techniques at room temperature and the time dependency was found to be close to the scaling law according to Eq. $6\left(\sim t^{1 / 2}\right)$. Also shown in Fig. 5 are data for a vertical panel exposed to a heated water film at $45^{\circ} \mathrm{C}$. A $50 \%$ increase is observed when the water temperature is increased from $20^{\circ} \mathrm{C}$ to $45^{\circ} \mathrm{C}$. This increase can be attributed to the decrease in viscosity and surface tension to some degree. However, these effects cannot account for the observed $50 \%$ increase in water absorption. Therefore, other causes such as fibrous swelling might be contributing to this increase in absorption. It appears that the absorbed mass remains proportional to the square root of exposure time when heated water is used. These tests show that temperature dependency is significant and should be included in the final model.

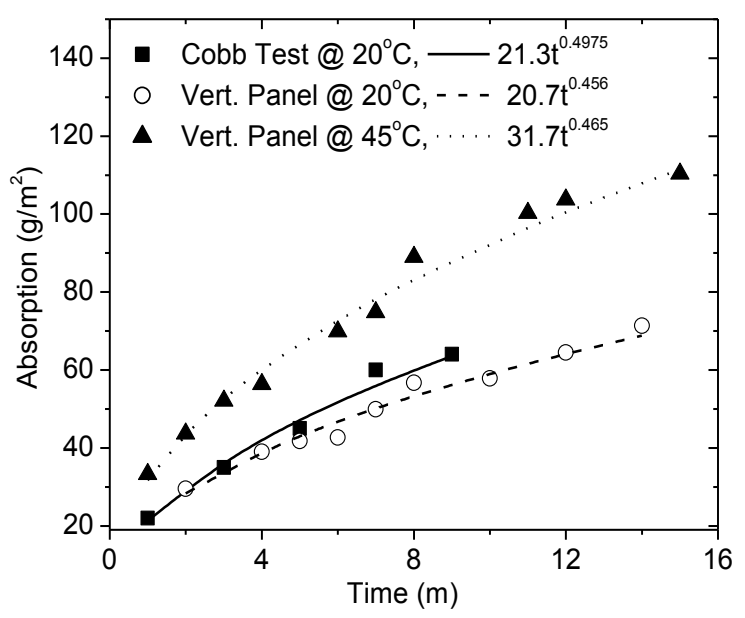

Fig. 5. Absorption results for Cobb tests and vertical panel tests.

\section{Vertical Wall Tests}

The vertical wall tests performed in this study includes evaporation tests, dry-spot formation tests, and ignition tests on wet corrugated cardboard. Results from these tests will be discussed now.

\section{Evaporation Tests}

Evaporation experiments were carried out on a back-insulated, thin aluminum plate exposed to radiant heat fluxes. The front of the panel was painted with carbon black to create near unity absorptivity $(\alpha=0.96)$. Within the exposed area of 46 by $41 \mathrm{~cm}$, the difference between maximum and average heat flux was less that $10 \%$. Flow rates ranging from 3 to $19 \mathrm{~g} / \mathrm{s}$ were used in this study. The measured evaporation rates relate to the source term in Eq. 1 as $\Delta m_{v a p}=\int_{0}^{L_{x}} \int_{0}^{L_{y}} \int_{0}^{t_{a b s}} S_{\rho \delta, v a p} d x d y d t$, where $L_{x}$ and $L_{y}$ are the dimension of the evaporation area in the experiment and $t_{a b s}$ is the test duration. Figure 6 shows evaporation rates versus heat flux with radiant heat fluxes ranging from 20 to $40 \mathrm{~kW} / \mathrm{m}^{2}$, and water flow rates ranging from $3.6 \mathrm{~g} / \mathrm{s}$ to $18.9 \mathrm{~g} / \mathrm{s}$. Water inlet temperatures were $15^{\circ} \mathrm{C}$. A clear monotonic increase in evaporation rate is seen with increasing heat flux. Also, evaporation rates decrease with increasing water flow rates up to $12.6 \mathrm{~g} / \mathrm{s}$, after which increasing the water-flow rate further did not affect the evaporation rate.

\section{Rivulets and Dry Spots}

When a fully-covered, uniform water film is suddenly exposed to a radiant heat flux, surface tension gradients can cause dry spots to form on the surface. The dry spots, no longer cooled by a water film, will subsequently heat up, pyrolize, and transfer heat to the contact line. Water flowing alongside the contact 
line will experience a temperature increase causing its surface tension to reduce further and for the dry spots to grow. Given sufficient heat flux, the water film will completely break up and only discrete rivulets will remain. Bare, exposed fuel surfaces are then free to pyrolize and burn, and may further increase the evaporation rate and break up adjacent water film. Therefore, the critical water flow rates required to form dry spots for a given radiant heat flux are of great interest, and were measured in the present work on an aluminum surface similar to that used for the evaporation tests. Figure 6 shows that for flow rates greater than $12.6 \mathrm{~g} / \mathrm{s}$, the wall becomes sufficiently flooded and the evaporation will solely be caused by radiant absorption of the top layer of the water film. Hence, the plots will look similar for these conditions.

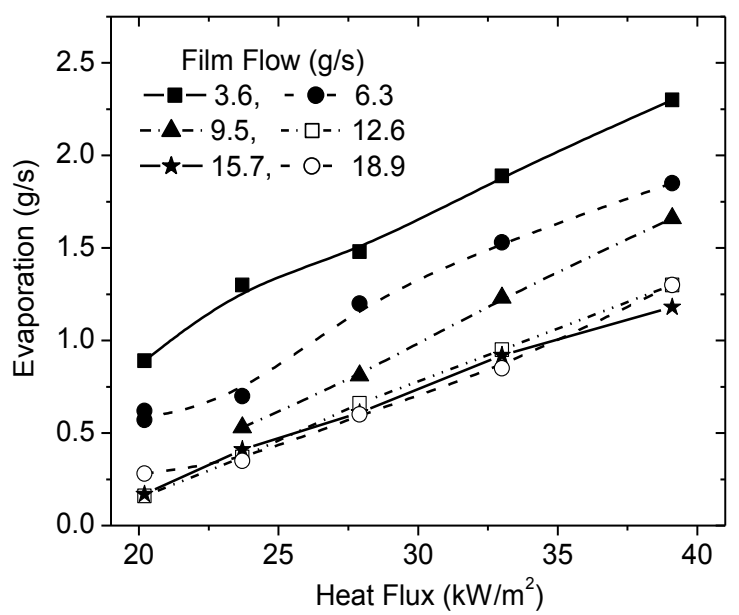

Fig. 6. Evaporation rates for vertical water films exposed to radiant heat flux.

Figure 7 shows flow rates at which dry spots were formed versus radiant heat flux. A monotonic increase in critical flow rate is observed with increasing heat flux. Some scatter is visible at lower flow rates caused by difficulties in creating a uniform film under these conditions.

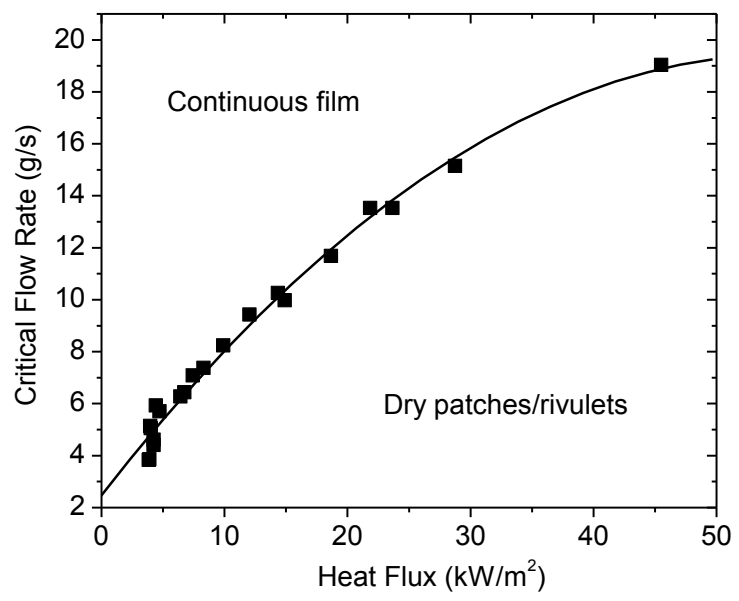

Fig. 7. Critical flow rates for rivulet formation.

Formation of dry spots was also observed on tri-wall corrugated cardboard used for suppression experiments, which clearly affects the pyrolysis area on the fuel surface. Rivulet flow and the formation of dry spots may have significant impact on water-film suppression and are incorporated in the numerical model [12] through the capillary pressure term $p_{\sigma}$ and the contact angle force term $\mathbf{F}_{\theta}$. 


\section{Ignition of Corrugated Tri-wall Paperboard}

Ignition tests were performed with dry surfaces and surfaces pre-exposed to a water film for a set amount of time (2, 5, and $10 \mathrm{~min})$. Given these exposure times, the total amount of water absorbed into the top layer of the corrugated tri-wall paperboard was calculated from absorption tests performed previously. Earlier work by Khan et al. [20] using a fire propagation apparatus (FPA), showed the effect of moisture content (4-12.5\%) on the ignition time of tri-wall corrugated cardboard samples, and found that corrugated cardboard samples could be modeled as thermally-thin solids for incident heat fluxes up to $50 \mathrm{~kW} / \mathrm{m}^{2}$. Figure 8 show ignition results from this study using tri-wall corrugated cardboard panels with calculated moisture content close to $5.6 \%$. Good agreement is seen between ignition data obtained using a FPA and the results from this study. Also shown in Fig. 8 is the result from a theoretical model presented by Khan et al. [20] assuming thermally thin conditions, a critical heat flux of $8.5 \mathrm{~kW} / \mathrm{m}^{2}$, and an ignition surface temperature of $623 \mathrm{~K}$. Good agreement is seen between the model and the measurements from ref. [20].

The effect of absorbed water on ignition behavior was studied by exposing corrugated tri-wall cardboard panels to a water film for two, five, and ten minute periods. After this time period, the liquid water present on the surface was quickly removed leaving only the absorbed water in the top layer. Using the relationship shown in Fig. 4, this would result in an absorbed water mass of 28,43 , and $59 \mathrm{~g} / \mathrm{m}^{2}$, respectively. These results are equivalent to moisture content (MC) levels of 15, 20, and $25 \%$ under the assumption that absorption only occurs on the top layer. After water exposure, the surface water was wiped of and the sample was exposed to a known radiative heat flux $\left(11-35 \mathrm{~kW} / \mathrm{m}^{2}\right)$. The effect of absorbed water on ignition is shown in Fig 8. Delays in ignition times of 20 to $60 \%$ are seen due to absorbed water. The surface layer of absorbed water disappears quickly (on the order of seconds). Therefore, the relative effect of this water is more profound at shorter ignition time, i.e., at higher heat fluxes.

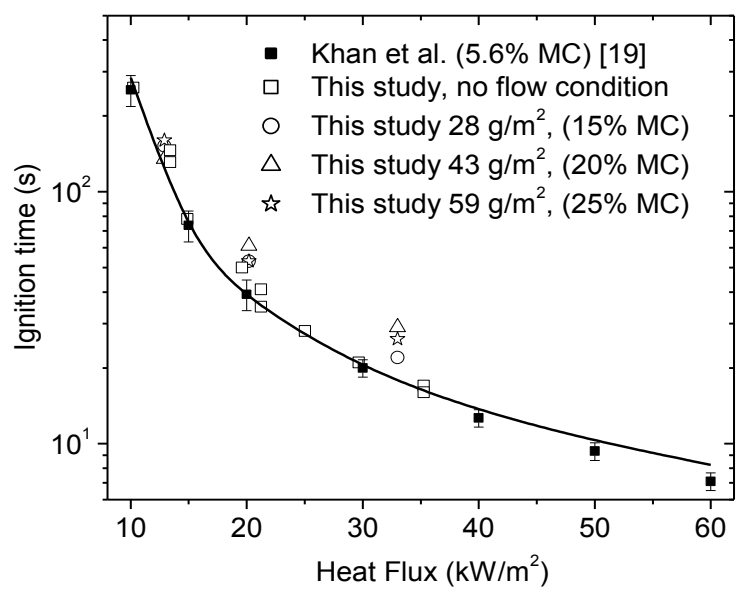

Fig. 8. Ignition times on vertical corrugated cardboard slabs with and without pre-exposure to a water film.

\section{Water Transport in Rack Storage}

The gross efficiency of water transport is defined as the fraction of nominal applied water flux delivered to the bottom of the vertical walls of the corrugated cardboard boxes at each tier. Since there is water impingement on the sidewalls of the boxes on the first tier, the efficiency based on the nominal applied water flux can exceed unity under certain conditions. Figure 9 shows the gross efficiencies for different tiers and water fluxes. The tier-to-tier transport in rack storage can result in water loss due to absorption, splashing, evaporation and misalignment of commodities. It can be seen that the transport efficiency generally decreases with increasing water flux and number of tiers passed, so that up to $25 \%$ of the applied water flux $\left(24.4 \mathrm{~L} / \mathrm{min} \cdot \mathrm{m}^{2}\right)$ can be lost by the third tier. Both rack storage with and without pallets were examined in this study and the general trends are largely consistent for both cases. Based on the water absorption rates measured before, water absorption only accounts for $1.7 \%$ loss at the lowest flow rate, which can not explain the large loss in transport efficiency as shown in Fig. 8. Therefore, water loss due to 
splashing around the edges and misalignment of the commodities needs to be considered in water transport modeling.

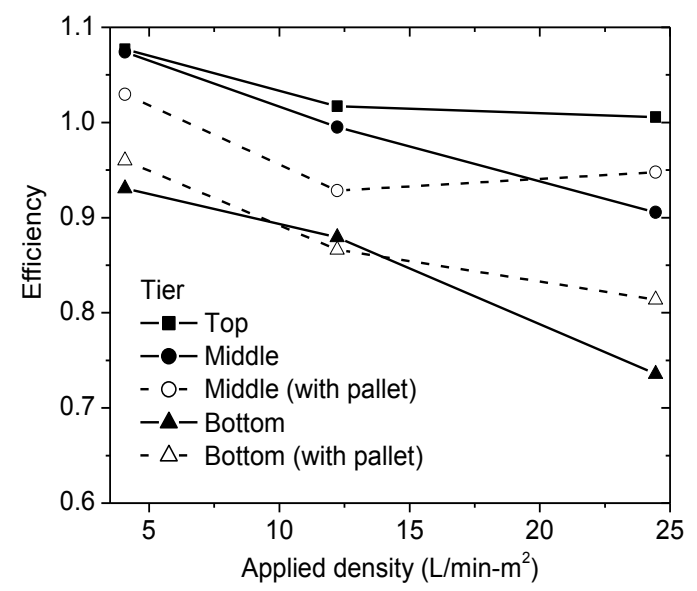

Fig. 9. Gross efficiency of water transport in rack storage of Class 2 commodities.

In addition to the gross efficiency of water transport, the uniformity of the water flow around the vertical walls of each box was examined by comparing the standard deviation and the mean of 48 measurements. The results show that, under most experimental conditions, the standard deviation can reach or exceed $100 \%$ of the average flow rate measured. The highly non-uniform distribution of the water flows can be attributed to a number of factors, such as the levelness of the rack/corrugated cardboard boxes, the tier-totier alignment of the boxes, and the imperfect cubic shape of the boxes with packaging details such as the taped top surface, the glued bottom surface, the seams, and the folded (smooth) and non-folded (sharp) edges. Given the magnitude of the non-uniformity, its impact on overall fire suppression behavior deserves further investigation.

\section{Parallel Panel Tests}

Eleven suppression tests were performed using parallel panels. Water flow rates ranging from 0 (freeburn) to $14 \mathrm{~g} / \mathrm{s}$ were applied to the corrugated cardboard panels before ignition. These water flow rates are equivalent to an applied water flux of $0-2.4 \mathrm{~L} / \mathrm{min} \cdot \mathrm{m}^{2}$ on top of Class 2 commodities based on the nominal flow rate per unit width generated on the vertical surfaces of the commodity. Heat release rates were determined using measured $\mathrm{CO}_{2}$ and $\mathrm{CO}$ concentrations and the mass flow rate in the FPC exhaust duct. The net heat of complete combustion per unit mass of combustion products generated was taken from Ref. [21]. For each test, the heat release rate by the propane burner was subtracted from the measured total heat release rate. Figure 9 shows the heat released during the first $100 \mathrm{~s}$ after ignition versus applied water flow rate (solid squares). This time period was selected since significant burning was often completed after the first $100 \mathrm{~s}$. Also plotted in Fig. 10 are the maximum heat release rates recorded during the tests (open squares). Freeburn tests performed in this study agree well with experiments performed by Krishnamoorthy et al. (open circles). Figure 10 shows that, with increasing water flow rate, the burning behavior of the triwall corrugated cardboard changed significantly in terms of the total chemical energy and the maximum heat release rate. Therefore, this type of experiment provides appropriate data to evaluate the suppression model. 


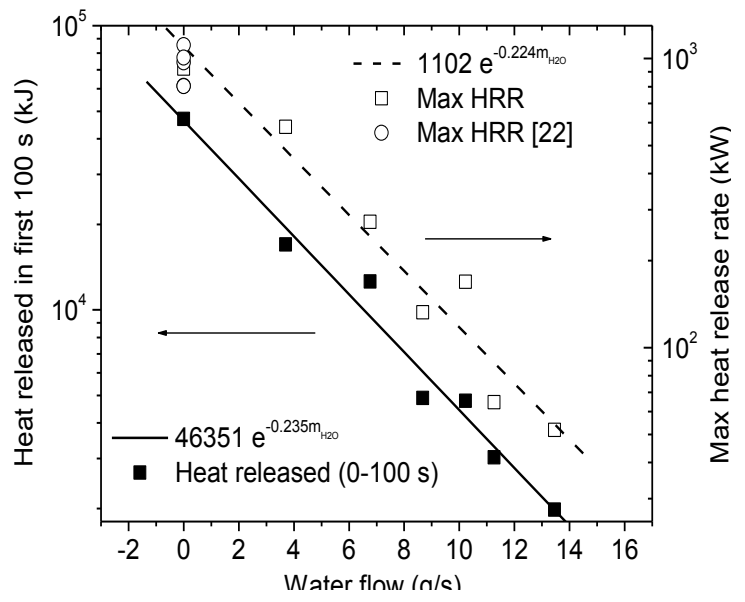

Fig. 10. Heat released in first hundred seconds $(\mathrm{kJ})$ and maximum measured heat release rate $(\mathrm{kW})$ versus water flow rate $(\mathrm{g} / \mathrm{s})$.

\section{SUMMARY}

The physical phenomena associated with fire suppression using sprinklers were investigated experimentally. A framework for numerical modeling of sprinkler suppression was outlined and the key physical effects for model development were identified. Preliminary experimental data were obtained, with an emphasis on evaluating the experimental methods. The physical phenomena considered in this work include water absorption by porous fuels, water transport in rack storage configurations, water evaporation and wet fuel ignition on vertical walls with external radiation, and water suppression on vertical-walls and parallel panels.

The experimental studies showed that

- The accumulated mass of water absorption by vertical corrugated paperboard scales with the square root of the exposure time. The total amount of water absorbed is small compared to total water flows applied.

- The tier-to-tier transport of water in rack storage of idealized Class 2 commodities is sensitive to applied water flux, with increasing loss fraction as the applied water flux and the number of tiers increases. The water flow on vertical surfaces of the idealized Class 2 commodity exhibits highly non-uniform distributions, whose significance to fire suppression deserves further investigation.

- The water evaporation on vertical surfaces is sensitive to external heat flux, which also alters the flow pattern, i.e., transition from films to rivulets with increasing external heat flux. The water evaporation rate can be quantified reasonably well using either a mass balance method or direct humidity measurements.

- Suppression experiments using a single-wall set-up and parallel panels revealed the impact of continuous wetting on fire growth, through the analysis of ignition times and integrated and maximum heat release. The measured ignition times on single-wall of pre-wetted corrugated cardboard agree well with previous data obtained using the FPA, while significant change of chemical release and maximum burning rates were observed in the parallel panel tests.

Overall, the results showed that the experimental methods examined in the present work are appropriate for studying the physics associated with sprinkler-based fire suppression. These experimental methods should be further improved to provide quantitative measurement to guide model development and provide data for the validation of the modeling framework designed to simulate fire suppression using sprinklers.

\section{FUTURE WORK}

Based on this experimental study, future work will focus on detailed investigations of key suppression physics and repeated measurements for model validation. The physical phenomena that require further study include temperature effects on absorption, film-to-rivulet transition, statistical characteristics of 
rivulets, water splashing in the vicinity of box edges and water flow over single and multiple corrugated cardboard boxes. To validate the suppression model, measurements are needed for water evaporation rates on vertical walls subject to external radiation, and heat release rates in parallel panel tests with pre-wetted fuels. Results from the suppression studies will be incorporated in the basic water transport model that is being integrated with the rest of the FireFOAM code. Validation of the integrated model will be then conducted using the single-wall and parallel panel experiments, and finally water application tests and fullscale sprinkler tests using Class 2 commodities in rack storage.

\section{ACKNOWLEDGEMENTS}

The authors would like to acknowledge Dr Hong-Zeng Yu, Dr Xiangyang Zhou, Dr Yi Wang and Dr Francesco Tamanini for invaluable discussions on experimental methods and modeling approach, and $\mathrm{Dr}$ Robert Bill Jr., Dr Sergey Dorofeev and Dr Louis Gritzo for their encouragement of this work. The authors would also like to thank Mr Stephen D'Aniello and FM Global Research Campus staff for their help on instrumentation and experiments.

\section{REFERENCES}

[1] Grant, G., Brenton, J., and Drysdale, D., (2000) Fire Suppression by Water Sprays, Progress in Energy and Combustion Science 26: 79-130, http://dx.doi.org/10.1016/S0360-1285(99)00012-X

[2] Liu, Z. and Andrew K.K., (2000) A Review of Water Mist Fire Suppression SystemsFundamental Studies, Journal of Fire Protection Engineering, 10: 32-50, http://dx.doi.org/10.1177/104239159901000303

[3] Liu, Z. and Andrew K.K., (2000) A Review of Water Mist Fire Suppression Technology: Part IIApplication Studies, Journal of Fire Protection Engineering 11: 16-42, http://dx.doi.org/10.1106/MMGH-XUAG-HP5B-YTDG

[4] Wighus, R., "Water Mist Fire Suppression Technology - Status and Gaps in Knowledge," International Water Mist Conference, Vienna, 2001, p. 1-26.

[5] Yu, H.Z., 1986. Investigation of Spray Patterns of Selected Sprinklers with the FMRC Drop Size Measuring System. Fire Safety Science 1: 1165-1176, http://dx.doi.org/10.3801/IAFSS.FSS.1$\underline{1165}$

[6] Xia, J., Luo, K. and Kumar, S., 2009. Dynamic Interactions between a Buoyant Reacting Plume and Evaporating Droplets. Fire Safety Science 9: 627-638, http://dx.doi.org/10.3801/IAFSS.FSS.9-627

[7] Croce, A.C., Grosshandler, W.L., Bukowski, R.W., and Gritzo, L.A., (2008) The International FORUM of Fire Research Directors: A Position Paper on Performance-Based Design for Fire Code Applications, Fire Safety Journal, 43: 234-236, http://dx.doi.org/10.1016/j.firesaf.2007.12.004

[8] Wang, Y., Chatterjee, P., and de Ris, J.L., (2011) Large Eddy Simulation of Fire Plumes, Proceedings of the Combustion Institute, 33: 2473-2480, http://dx.doi.org/10.1016/j.proci.2010.07.031

[9] Chatterjee, P., de Ris, J.L., Wang, Y., and Dorofeev, S.B., (2011)A Model for Soot Radiation in Buoyant Diffusion Flames. Proceedings of the Combustion Institute, 2665-2671, http//dx.doi.org/10.1016/j.proci.2010.06.112

[10] Chaos, M., Khan, M.M., Krishnamoorthy, N., de Ris, J.L., and Dorofeev S.B., (2011) Evaluation of Optimization Schemes and Determination of Solid Fuel Properties for CFD Fire Models Using Bench-scale Pyrolysis Tests. Proceedings of the Combustion Institute, 33: 2599-2606, http//dx.doi.org/10.1016/j.proci.2010.07.018

[11] Zhou, X., D'Aniello S., and Yu, H.Z., "Spray Pattern Measurements of Selected Fire Sprinklers," $12^{\text {th }}$ International Conference on Fire Science and Engineering, Nottingham, UK, July, 2010, p. 177-188. 
[12] Meredith, K., de Vries, J., and Xin, Y., 2011 A Numerical Model for Simulation of Thin-Film Water Transport over Solid Fuel Surfaces, Fire Safety Science 10, accepted for publication.

[13] de Vries, J., D'Aniello, S., and Xin, Y., Water Flows on Vertical Surface and around Corners of Corrugated Cardboards for Sprinkler Protection of Rack Storage, $12^{\text {th }}$ International Conference on Fire Science and Engineering, Nottingham, UK, July, 2010, p. 143-152.

[14] TAPPI Standard T 441 om-04 "Water absorptiveness of sized (non-bibulous) paper, paperboard, and corrugated fiberboard (Cobb test)" TAPPI, 2004.

[15] Lowe, P.R., (1977) An Approximating Polynomial for the Computation of Saturation Vapor Pressure, Journal of Applied. Meteorology 16: 100-103, http://dx.doi.org/10.1175/15200450(1977)016<0100:AAPFTC >2.0.CO;2

[16] Kline, S.J. and McClintock, F.A., (1953) Describing Uncertainties in Single-Sample Experiments, Mechanical Engineering, 75: 3-8.

[17] Jayaweera, T. M. and Yu, H-Z., (2006) Water Absorption in Horizontal Corrugated Boards under Water Sprays, Fire Safety Journal 41: 335-342, http://dx.doi.org/10.1016/j.firesaf.2006.01.007

[18] Lucas, R., and Kolloid Z., (1918) Ueber das Zeitgesetz des Kapillaren Aufstiegs von Flussigkeiten, Colloid \& Polymer Science 23: 15-22, http://dx.doi.org/10.1007/BF01461107

[19] Washburn, E.W., (1921) The Dynamics of Capillary Flow, Physical Review 17: 273-283, http://dx.doi.org/10.1103/PhysRev.17.273

[20] Khan, M.M., De Ris, J.L. and Ogden, S.D., 2009. Effect of Moisture on Ignition Time of Cellulosic Materials. Fire Safety Science 9: 167-178, http://dx.doi.org/10.3801/IAFSS.FSS.9-167

[21] Tewarson, A., "Generation of Heat and Gaseous, Liquid, and Solid Products in Fires," The SFPE Handbook of Fire Protection Engineering ( $4^{\text {th }}$ ed), DiNenno, P.J. (ed.), National Fire Protection Association, Quincy, MA 02269, 2008, p. 3/109.

[22] Krishnamoorthy, N., Chaos, M., Khan, M.M., Chatterjee, P., Wang, Y., Dorofeev, S., Application of Bench-Scale Material Flammability Data to Model Flame Spread in Medium-Scale Parallel Panel Tests", $12^{\text {th }}$ International Conference on Fire Science and Engineering, Nottingham, UK, July, 2010, p. 709-720. 